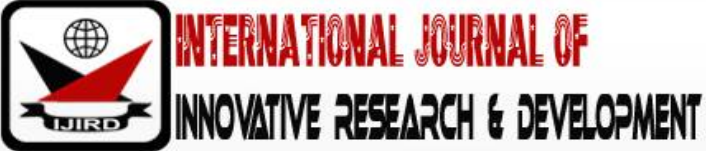

ISSN 2278-0211 (Online)

\section{Staff Incentives and Implementation of Financial Inclusion Strategy by Insurance Firms in Kenya}

Nathan Chizotera Mkandawire
Ph.D. Candidate, Department of Business Administration
Kenya Methodist University, Kenya
Dr. Thomas Anyanje Senaji
Deputy Vice Chancellor, Department of Academics, The East African University, Kenya
Dr. Eunice Karegi Kirimi
Senior Lecturer, Department of Business Administration, Kenya Methodist University, Kenya

\begin{abstract}
:
Strategy implementation presents the greatest challenge to organisations for various reasons one among them being insufficient alignment of staff incentives with the strategy to be implemented. The aim of this study was to examine the relationship between strategic staff incentives and performance of insurance firms in Kenya specifically focusing on financial inclusion strategy. Drawing from the Herzberg's two-factor theory, a cross-sectional survey of 48 permanent employees from 12 insurance firms was conducted using structured questionnaires in order to ascertain the relationship between strategic staff incentives comprising pay, oversight, meaningfulness of work, employee growth and job security are applied and how they relate to the level of performance as observed through the extent of financial inclusion indicators measured by access, usage, financial literacy and quality of service attained by these firms. The questionnaire items were anchored on a five-point Likert scale from 1=very dissatisfied to 5=very satisfied. It was found that the employees were dissatisfied with pay $(M=2.53)$ and growth opportunities $(M=2.56)$ and only moderately agreed that their jobs were meaningful $(M=3.85)$ and secure $(M=3.83)$; and that oversight $(M=3.54)$ was also moderately satisfactory. It was further found that both oversight and job security were significantly related with financial inclusion indicators, namely financial literacy and quality of financial services (Oversight/Financial literacy: $r=0.398, p=0.04<0.05$; Job security/Quality: $r=0.414, p=0.029<0.05)$. Oversight was also found to be significantly related with quality of service at $p<0.1$ (Oversight/quality: $r=0.32, p=0.09<0.1$ ). Based on these findings, it is recommended that management in insurance firms focus on providing effective oversight of staff because it had the most significant relationship with financial inclusion indicators. Similarly, job security should be ensured since it positively predicted quality of financial services provided by the insurance firms. Further, insurance companies should improve on their staff incentives since they were found to be largely unsatisfactory as reported by the survey respondents.
\end{abstract}

Keywords: Staff incentives, strategy implementation, financial inclusion, insurance firms, Kenya

\section{Introduction}

Studies have shown that close to $70 \%$ of the formulated strategies fail at implementation stage due to various reasons. Just like a map, a strategy can show us where we are, where we need to be and the way to get there. Although strategic direction is set by senior management, the implementation depends on the buy-in of everyone. Further, some of the, problems that limit the success of strategy implementation include lack of Buy-in by the staff, misalignment of resources, unrealistic time frames, deliberate vs emergent, the gaps are too large, things are expected to stay the same, inadequate or lack of monitoring, and when the formulated strategy does not engage the staff.

The aforelisted reasons for strategy implementation failure have received considerable empirical investigation. This notwithstanding, empirical literature for incentives to staff involved in the delivery/ implementation of strategies and how these incentives influence performance is scarce.

The study will draw from the Expectancy Theory of Motivation which deals with the relationship between effort and expected outcome; and Hertzberg's two-factor theories which deals with work and work place related factors that would enable staff to perform at the optimal levels. These theories are closely linked to the study variables. While incentives given to staff (pay, oversight, growth opportunities, meaningfulness of work and job security) are underpinned by Herzberg Theory, performance (the implementation of financial inclusion strategy) is anchored by the Expectancy theory which links rewards to performance In this study, the rewards are the five incentives while effectiveness of strategy implementation is performance.

In a nutshell, Frederick Herzberg (1959) came up with the two-factor theory (also known as Herzberg's motivation-hygiene theory and dual-factor theory) which states that there are certain factors in the workplace that cause 
job satisfaction, while a separate set of factors cause dissatisfaction. The hygiene factors cannot be regarded as motivators. The motivational factors yield positive satisfaction. These factors are inherent to work. These factors motivate the employees for a superior performance and are called satisfiers. Employees find these factors intrinsically rewarding. The motivators symbolized the psychological needs that were perceived as an additional benefit. Such factors include performance related pay, supervision, recognition, inner sense of achievement, growth and promotional opportunities, responsibility and meaningfulness of the work, and job security.

On the other hand, Expectancy theory (or expectancy theory of motivation) insinuates that an individual will behave or act in a certain way because of what would be the expected result of that chosen pattern of behaviour. In other words, the motivation to choose a certain behaviour is determined by the desired outcome.

According to Victor Vroom (1964) an employee's performance is based on individual factors such as personality, skills, knowledge, experience and abilities. Although incentives at organizational level are provided in financial institutions, the relationship between these incentives and performance is scarcely documented in empirical literature. Further, whether the performance of Financial Inclusion Institutions leads to achieving Kenya Central Bank's Financial Inclusion Strategy is still unclear. The broad research questions (RQs) to be answered by this study are:

- $\mathrm{RQ}_{1}$ : Do financial institutions offer sufficient incentives to their staff involved in the implementation of financial inclusion strategy?

- $\mathrm{RQ}_{2}$ : What is the relationship between staff incentives and performance of the financial inclusion institutions?

\section{Theory and Hypothesis}

We drew from the theories of motivation, particularly the two factor theory and from the financial inclusion literature and hypothesised that staff incentives (as posited by the two factor theory_ are related with implementation of financial inclusion strategy, comprising access, usage, financial literacy and quality of financial services. The incentives were pay (salary and allowances), oversight (or supervision), growth opportunities, meaningfulness of work, and job security.

According to the World Bank Multi-country Demand-side Data Survey on financial inclusion (2014), financial inclusion indicators can be used to help set national financial inclusion targets and monitor progress in reaching them. Thus, when policymakers have reliable performance indicators and survey mechanisms, they can diagnose the state of financial inclusion, agree on targets, identify barriers, craft policies as well as monitor and measure policy impact. The indicators can be in four categories as follows: -

\subsection{Access Indicators}

These indicators reflect the depth of outreach of financial services, such as the penetration of bank branches or point of sale (POS) devices in semi-urban and rural areas, or demand-side barriers that customers face to access financial institutions, such as cost or information.

\subsection{Usage Indicators}

The second category is usage indicators which measure how clients use financial services, such as the regularity and duration of the financial product/service over time (e.g. average savings balances, number of transactions per account, number of electronic payments made).

\subsection{Quality Measures}

These indicators describe whether financial products and services match clients' needs, the range of options available (products and services) to customers.

\subsection{Financial Literacy}

This is a fourth indicator which is the extent to which outreach educational programmes are implemented by financial institutions.

With the foregoing understanding of the staff incentives and financial inclusion, we hypothesised as follows:

- $\mathrm{H}_{01}$ : There are no sufficient incentives to staff involved in the implementation of financial inclusion strategy in insurance firms in Kenya

- $\quad \mathrm{H}_{02}$ : Strategic staff incentives have no significant relationship with implementation of financial inclusion strategy in insurance firms in Kenya

\section{Methodology}

We conducted an exploratory descriptive survey of 48 permanent employees from 12 insurance firms using a structured questionnaire to collect data on five staff incentives and from four proxies (measures) of financial inclusion (access, usage, financial literacy, and quality of financial services). Closed-ended questions were chosen because they have the following advantages: First, answers of the questions are known in advance (Senaji, 2012) and this facilitates faster analysis, and secondly, closed -ended questions have a better chance of being more reliable or consistent over time than open-ended questions because respondents can select the answer that better explains their response (Fink, 1995).

A five-point Likert type scale was used for data collection where the five possible responses were: 1=Very dissatisfied/ strongly disagree, 2=dissatisfied/disagree, 3=somewhat satisfied/agree, 4=satisfied/agree and 5=Very satisfied/ strongly agree. When performing data collection and subsequent analysis it is important to first check whether 
the questionnaire is reliable (Field, 2005). Cronbach's alpha is a reliability coefficient that is used to evaluate whether the items on a test instrument are consistent with one another in that they represent only one construct (Salkind, 2004).

Consequently, reliability test was carried out to determine the suitability of the questions in the questionnaires. Since some parts of the instrument that was adopted were previously validated a higher cut-off Cronbach alpha value of $\alpha$ $=0.7$ or higher was be used (Nunnaly, 1978). All the variables had a Cronbach of at least 0.7 and those that did not meet this threshold were adjusted by deleting some of the item measured that had been included in the initial questionnaire. The reliability results are presented in the leading diagonal of Table 4 together with the correlation results.

\section{Results and Discussion}

Out of the 48 responses that were received, 32\% were at management level while 68 were operation level staff. The staff were asked to indicate whether they were aware of how their salaries and allowances; and whether they had a financial including strategy. The results are presented in Table 1

\begin{tabular}{|c|c|c|c|c|}
\hline Statement & Response & Frequency & Percent & Cumulative Percent \\
\hline \multirow{3}{*}{$\begin{array}{c}\text { I am aware of how my salary } \\
\text { is determined }\end{array}$} & No & 8 & 18.2 & 18.2 \\
\cline { 2 - 5 } & Yes & 32 & 81.8 & 100 \\
\cline { 2 - 5 } & Total & 40 & 100 & \\
\hline \multirow{3}{*}{$\begin{array}{c}\text { I am aware of how my } \\
\text { allowances are determined }\end{array}$} & No & 12 & 27.3 & 27.3 \\
\cline { 2 - 5 } & Yes & 32 & 72.7 & 100 \\
\cline { 2 - 5 } & Total & 44 & 100 & 9.1 \\
\hline \multirow{2}{*}{$\begin{array}{c}\text { My institution has financial } \\
\text { inclusion strategy }\end{array}$} & No & 4 & 9.1 & 100 \\
\cline { 2 - 5 } & Yes & 40 & 90.9 & \\
\cline { 2 - 5 } & Total & 44 & 100 & \\
\hline
\end{tabular}

Table 1: Salaries, Allowances and Presence of Financial Inclusion Strategy

We also collected data on the duration of the financial inclusion strategy and the results are presented in Table 2.

\begin{tabular}{|c|c|c|c|}
\hline Duration of FI strategy & Frequency & Percent & Cumulative Percent \\
\hline Long term & 3 & 25 & 25 \\
\hline Medium term & 7 & 58.3 & 83.3 \\
\hline Short term & 2 & 16.7 & 100 \\
\hline Total & 12 & 100 & \\
\hline
\end{tabular}

Table 2: Duration of Financial Inclusion Strategy

As shown in Table 3, most of the firms (58.3\%) had medium term (3 to 5 years) financial inclusion strategy. In addition the programs and/ or projects that were covered by the firm's financial inclusion strategy were: expanding access to financial services (86.4\%), increasing the usage of financial service $(77.3 \%)$, educating the citizens on financial services (77.3\%), and improving the quality of financial services (90.9\%). According to this result, the focus of the FI strategy is on quality of services to customers and expanding access to financial services.

\subsection{Staff Incentives and Implementation of Financial Inclusion Strategy}

The staff incentives that were studied were pay (alary and allowances), oversight (supervision), growth opportunities, meaningfulness of work, and job security. In addition, the measures of implementation of financial inclusion strategy were access, uptake (usage), financial literacy and quality of financial services provided by the insurance firms. These performance indicators were used as proxies for the implementation of the financial inclusion strategy.

\begin{tabular}{|c|c|c|c|c|c|c|c|}
\hline & $\mathbf{N}$ & Mean & SD & \multicolumn{2}{|c|}{ Skewness } & \multicolumn{2}{c|}{ Kurtosis } \\
\hline Pay & 48 & 2.53 & 0.85 & 0.417 & 0.441 & -0.282 & 0.858 \\
\hline Oversight (supervision) & 48 & 3.54 & 0.95 & -0.222 & 0.441 & -0.352 & 0.858 \\
\hline Growth opportunities & 48 & 2.56 & 0.95 & 0.206 & 0.441 & -0.49 & 0.858 \\
\hline Meaningfulness & 48 & 3.85 & 0.59 & -0.54 & 0.441 & 0.584 & 0.858 \\
\hline Job security & 48 & 3.83 & 0.61 & -0.882 & 0.441 & 1.295 & 0.858 \\
\hline Composite mean & & 3.26 & 0.67 & & & & \\
\hline Access to financial services & 48 & 3.61 & 0.73 & -1.47 & 0.441 & 3.989 & 0.858 \\
\hline Usage (Uptake) of financial & 48 & 3.97 & 0.61 & -0.11 & 0.441 & 0.217 & 0.858 \\
\hline services & & & & & & & \\
\hline Financial literacy & 48 & 3.19 & 0.82 & 0.241 & 0.441 & -0.652 & 0.858 \\
\hline Quality of financial services & 48 & 4.09 & 0.66 & -0.505 & 0.441 & 0.407 & 0.858 \\
\hline Valid N (listwise) & 48 & & & & & & \\
\hline
\end{tabular}

Table 3: Incentives and Implementation of Financial Inclusion Strategy

The employees were least satisfied with the pay and growth opportunities (Pay: $\mathrm{M}=2.53$, SD = 0.85; Growth opportunity: $M=2.56, S D=0.95)$. Further, their job was moderately meaningful $(M=3.85, S D=0.59)$ and secure $(M=$ 
$3.83, \mathrm{SD}=0.61)$; and that they were satisfied with the level of service they provided $(M=4.09, \mathrm{SD}=0.66)$. The least satisfactory measure of financial inclusion was financial literacy $(M=3.19, \mathrm{SD}=0.82)$ followed by the level of access to financial services $(M=3.61, S D=0.61)$. The composite mean score for all the five staff incentives was $M=3.26$ and $S D=0.66$ respectively while the $t$-statistic associated with the difference between the composite mean and agreement on the existence of satisfactory incentives $(M=4.00)$ was $t=-2.478(t<-1.96)$. This result implies that the composite mean for all the staff incentive variables was significantly less than the expectation of 'satisfied/agreed' ( $M=4.00$ on a scale of 1 to 5 where 1 = very dissatisfied/ strongly disagree and $5=$ very satisfied/strongly agree).

\subsubsection{Testing of the First Hypothesis, $\left(\mathrm{H}_{01}\right)$}

Since the composite mean on the extent of satisfaction/agreement $(M=3.26)$ on the adequacy of incentives was significantly below $(t=-2.478, p<0.05)$ the expected level of at least $M=4.00$, the null hypothesis that Financial institutions do not provide sufficient incentives to their staff involved in the implementation of financial inclusion strategy in insurance firms in Kenya was accepted.

\subsubsection{Relationship between Incentives and Implementation of Financial Inclusion Strategy}

The result of the correlation analysis which was used to determine the strength of the relationship between staff incentives and financial strategy implementation (as measured by performance indicators) is presented on Table 4 . Reliability results for all the variables are presented in leading diagonal.

\begin{tabular}{|c|c|c|c|c|c|c|c|c|c|c|}
\hline & Variable & $\mathbf{1}$ & $\mathbf{2}$ & $\mathbf{3}$ & $\mathbf{4}$ & $\mathbf{5}$ & $\mathbf{6}$ & $\mathbf{7}$ & $\mathbf{8}$ & $\mathbf{9}$ \\
\hline 1 & Pay & 0.835 & & & & & & & & \\
\hline 2 & Oversight & 0.25 & 0.914 & & & & & & & \\
\hline & & 0.2 & & & & & & & & \\
\hline 3 & Growth opportunities & $.412^{*}$ & $.499^{* *}$ & 0.752 & & & & & & \\
\hline & & 0.03 & 0.01 & & & & & & & \\
\hline 4 & $\begin{array}{c}\text { Meaningfulness of } \\
\text { work }\end{array}$ & 0.18 & -0.05 & 0.128 & 0.943 & & & & & \\
\hline & & 0.35 & 0.81 & 0.517 & & & & & & \\
\hline 5 & Job security & 0.33 & 0.37 & $.428^{*}$ & 0.271 & 0.840 & & & & \\
\hline & 0.09 & 0.06 & 0.023 & 0.163 & & & & & \\
\hline 6 & $\begin{array}{c}\text { Access to financial } \\
\text { services }\end{array}$ & -0.04 & 0.12 & 0.043 & -0.055 & -0.118 & 0.740 & & & \\
\hline & & 0.83 & 0.54 & 0.828 & 0.783 & 0.55 & & & & \\
\hline 7 & $\begin{array}{c}\text { Uptake of financial } \\
\text { services }\end{array}$ & -0.17 & 0.31 & 0.27 & -0.117 & -0.013 & $.484^{* *}$ & 0.835 & & \\
\hline & & 0.4 & 0.11 & 0.165 & 0.553 & 0.949 & 0.009 & & & \\
\hline 8 & Financial Literacy & 0.1 & $.398^{*}$ & 0.266 & 0.271 & 0.301 & 0.092 & $.568^{* *}$ & 0.949 & \\
\hline & & 0.6 & 0.04 & 0.171 & 0.163 & 0.12 & 0.643 & 0.002 & & \\
\hline 9 & $\begin{array}{c}\text { Quality of insurance } \\
\text { services offered }\end{array}$ & -0.06 & 0.32 & 0.083 & 0.133 & $.414^{*}$ & 0.028 & $.396^{*}$ & $.582^{* *}$ & 0.762 \\
\hline & & 0.78 & 0.09 & 0.673 & 0.499 & 0.029 & 0.887 & 0.037 & 0.001 & \\
\hline & & 48 & 48 & 48 & 48 & 48 & 48 & 48 & 48 & 48 \\
\hline
\end{tabular}

Table 4: Relationship between Incentive Sand Financial Inclusions

* Correlation Is Significant at the 0.05 Level (2-Tailed)

** Correlation Is Significant at the 0.01 Level (2-Tailed)

Oversight was positively significantly related with financial literacy $\left(r=.398^{*}, \mathrm{p}=.04<.05\right)$. In addition, job security was positively and significantly related with quality of service offered by the firms $(r=.414, p=.029<.05)$. Similarly, oversight and quality of financial services are significantly related at $\mathrm{p}<.1(\mathrm{r}=.32, \mathrm{p}=.09<.1)$. Further, as expected uptake (usage) was significantly related with quality of service $(r=.396, p=.037<.05)$; and similarly, financial literacy was also positively and significantly related with uptake (usage) of financial services. $(r=0.568, p=.002<.05$ ). These results suggest that the higher the quality of oversight (an incentive) the higher would be the provision of financial literacy to the customers and this would lead to the uptake of financial services. These findings also suggest that the more the staff found their jobs secure (an incentive) the more they would be motivated to provide high quality financial services to their clients

Overall, these findings suggest the existence of a positive relationship between strategic staff incentives, particularly oversight and job security, and implementation of financial inclusion strategy as measured by performance indicators of access, usage, financial literacy and quality of services. The relationship was particularly significant with financial literacy and quality of services but not with access to and usage of services. Further, Pay, growth opportunities, 
and meaningfulness of work (all with $\mathrm{p}>0.1$ ) did not have a significant relationship with implementation of financial inclusion strategy.

\subsubsection{Testing of the First Hypothesis, $\left(\mathrm{H}_{02}\right)$}

The findings of this study are that not all staff incentives had a significant relationship with the implementation of financial inclusion strategy in insurance form in Kenya. Consequently the hypothesis that, Strategic staff incentives have no significant relationship with implementation of financial inclusion strategy in insurance firms in Kenya, was partially accepted on the basis that only oversight and job security hand a positive significant relationship with some financial inclusion measures (financial literacy and quality of financial services)

It is also noted that the finding on the relationship between pay and implementation of financial inclusion strategy implementation contradicts that of Bevan (2000), who asserted that pay systems have the dramatic potential to be one of the biggest positive influencers on employee behavior and performance.

With regard to oversight (or supervision) Radomska (2014), found that the strategic awareness that manifests itself by the assignment of tasks and decision making power is more important than the managers knowledge and additional skills. In this regard, it is noted that assignment of tasks is done by supervisors and that this assignment is contingent upon the supervisors awareness of the abilities of the employees they supervisor. Thus the finding on the relations between oversight and financial inclusion strategy implementation is consistent with Radomska's (2014) finding on the positive effects of supervision on strategy implementation.

Further, it has been extensively documented in most empirical literature, particularly with regard to Herzberg's' two factor theory, that that all the five incentives positively influence performance - including strategy implementation. Therefore, to the extent that some of these factors were not found to be significantly related with performance (in this case strategy implementation), a possible explanation would be that the incentives (particularly, pay: $M=2.53$; growth opportunities: $\mathrm{M}=2.56$; and meaningfulness of work: $\mathrm{M}=3.85$ ) were not high enough to significantly predict effectiveness of the implementation of financial inclusion strategy in insurance firms in Kenya.

\section{Conclusion and Implications}

The financial inclusion strategy implementation was being moderately achieved $(3.0<\mathrm{M}<4.0)$ hence more needed to be done to realise full implementation. The manner in which salaries and allowances were determined were not known to employees in the firms that were surveyed and that most of the insurance firms had a financial inclusion strategy most of which were medium term ( 3 to 5 years). Further, both oversight and job security were significantly related with financial inclusion indicators, namely financial literacy and quality of financial services (Oversight/Financial literacy: $\mathrm{r}=$ $0.398, p=0.04<0.05$; Job security / Quality: $r=0.414,0.029<0.05$ ). Oversight was also found to be significantly related with quality of service at $\mathrm{p}<0.1$ (Oversight/quality: $\mathrm{r}=0.32, \mathrm{p}=0.09<0.1$ ).

A number of conclusions can be drawn from these findings. First, oversight is the most important predictor of the success of the implementation of financial inclusion strategy. Secondly, there appeared to be no significant relationship between all the staff incentives (Pay, Oversight, Growth opportunities, Meaningfulness of work and Job security) and two attributes of financial inclusion strategy, namely access to and usage yet these two are important aspects of financial inclusion. Thirdly, these findings suggest that the staff incentives provided to employees were largely below the expectations of the employees $(M<4)$ and should be improved. Further, oversight and job security were most significant predictors of implementation of financial inclusion strategy.

\section{Recommendation}

Based on these findings, it is recommended that management in insurance firms focus on providing effective oversight of staff because it had the most significant relationship with financial inclusion indicators. Similarly, job security should be ensured since it positively predicted quality of financial services provided by the insurance firms. Further, insurance companies should improve on their staff incentives since they were found to be largely unsatisfactory as reported by the survey respondents.

Lastly, since the sample that was surveyed was small, a larger survey is recommended to increase the generalizability of the findings of this study. It is also recommended that more studies be conducted to establish whey there appeared to be no significant relationship between staff incentives and two attributes of financial inclusion, namely access and usage yet these two are important aspects of financial inclusion.

\section{References}

i. Bevan, S. (2000). Reward strategy: Ten Common Mistakes. Institute for Employment Studies. Retrieved April 10, 2019 from https://www.employment-studies.co.uk/system/files/resources/files/mp2.pdf

ii. Field, A. (2005). Discovering statistics using SPSS. (2ed.). London: Sage.

iii. Fink, A. (1995). How to measure survey reliability and validity (Vol. 7). Thousand Oaks, CA: Sage Publications.

iv. Herzberg, F. (1959). The motivation to work. New York: Wiley.

v. Nunnaly, J. (1978). Psychometric Theory. 2nd Edition. New York: McGraw Hill.

vi. Radomska, J. (2014). The Role of Managers in Effective Strategy. International Journal of Contemporary Management, 13 (3), 77-85.

vii. Salkind, Neil, J. (2004). An Introduction to theories of Human development. Thousand Oaks, CA: Sage Publications, Inc. 
viii. Senaji, T. A. (2012). Knowledge Management Infrastructure Capability, Motivation and Organisational Effectiveness among Mobile Telecommunications Service Firms in Kenya. PhD Thesis. Kenya Methodist University ix. Vroom, V. H. (1964). Work and Motivation. New York: Wiley

x. World Bank Group (2014). Finance and Markets: template for the design of a National Financial Inclusion. 